\title{
Application of clustering analysis in oil wells corrosion and scaling management
}

\author{
Xuanqi Yan ${ }^{1, a}$, Gang Xie ${ }^{1, a}$, Qingzhen Du1,a, Weiqi Jiang ${ }^{1, a}$, Yingrui Wang ${ }^{1, a}$, \\ Zhonghai Qin ${ }^{1, a}$, Yanping Miao ${ }^{2, b}$, Yanjun Wang ${ }^{3, c}$, Gang Yuan ${ }^{4, d}$
}

1Oil Production Engineering Institute of Huabei Oilfield Company, Renqiu, Hebei, China

1Cooperative development project department of Huabei Oilfield Company, Renqiu, Hebei, China

2The Third Oil Production Plant of Huabei Oilfield Company, Bazhou, Hebei, China

3Huabei Petroleum Tiancheng Industrial Group Co. Ltd., Renqiu, Hebei, China

4Huabei Petroleum Lide Construction Engineering Co. Ltd., Renqiu, Hebei, China

aemail: cyy_yxq@petrochina.com.cn, cyy_duqz@petrochina.com.cn

Keywords: corrosion, scaling, principal component analysis, clustering analysis

Abstract: This article demonstrates a method to make classification and dosing control for oil wells. To find the main factors that caused the corrosion and scaling in oil wells, water quality data of one oil production plant were made principal component analysis. Then the oil wells were divided into four types by using spss 19.0 clustering analysis software according to the differences among main factors. Finally, wells dosing were applied in the field according to the classification. The effect is obvious, the corrosion inhibition rate can reach $70 \%$ above, and scale inhibition rate of calcium carbonate can reach $90 \%$ above. Costs savings of all the wells add up to 5390 thousands.

\section{Introduction}

Corrosion and scaling in oil wells is one of the key factors to cause oil wells exhaustive pumping that seriously affects the normal production of oilfield ${ }^{[1]}$. There are many complex fault blocks in Huabei oilfield, with the continuous production of oilfield, the available under-ground water suffers from a gradual build-up of salinity. The erosive ions such as $\mathrm{Cl}^{-}, \mathrm{HCO}_{3}{ }^{-}, \mathrm{Ca}^{2+}, \mathrm{Mg}^{2+}$, et al in water have great effects on the corrosion and scaling in oil wells ${ }^{[2,3]}$. At present, the common method is to determine the main factors affected corrosion and scaling in each well by means of analyzing the water quality of each single well, and then take separate dosing control. However, the main problem is that dosing control of each single well is so much workload that it's difficult to form scale classification management. In view of the fact that the corrosion and scaling in oil wells is the result of multiple factors, the previous single factor analysis could not reflect the overall situation. In order to improve the comprehensive management level of oil wells, it is necessary to form a regular method to guide on-site work.

Yongbin Xiang et $\mathrm{al}^{[4]}$ classified the water quality data of Lasa city by using cluster analysis method combination with the main water quality survey data. Its credibility was extremely high, applied to environmental quality evaluation. Jingxin $\mathrm{Su}$ et $\mathrm{al}^{[5]}$ used cluster analysis to classify the corrosion environment of base airport, obtained four kinds of corrosion environmental regions with similar effects on corrosion behavior of the aircraft. The research results had important value for selecting parameters of civil airport corrosion accelerated test. Gehong Wu et al ${ }^{[6]}$ used cluster analysis to classify the reservoir physical property of Horqin oilfield, solved the reservoir classification problem, it had guiding significance for the next step development of classified reservoirs. Though cluster analysis has been applied in various fields of oilfield ${ }^{[7-11]}$, but it had seldom application in oil wells management. This article demonstrates the novel approach of corrosion and scaling in Huabei Oilfield by using cluster analysis, and proposes dosing methods to solve the problems of oil wells corrosion and scaling in ten different fault blocks. 


\section{Clustering analysis methods}

Different water quality data of an oil production plant were made clustering analysis by using spss19.0 software. The process of cluster analysis mainly contains (Fig.1) descriptive statistics analysis ${ }^{[12]}$, data standardization, establishing approximate coefficient matrix, principal component analysis and cluster analysis.

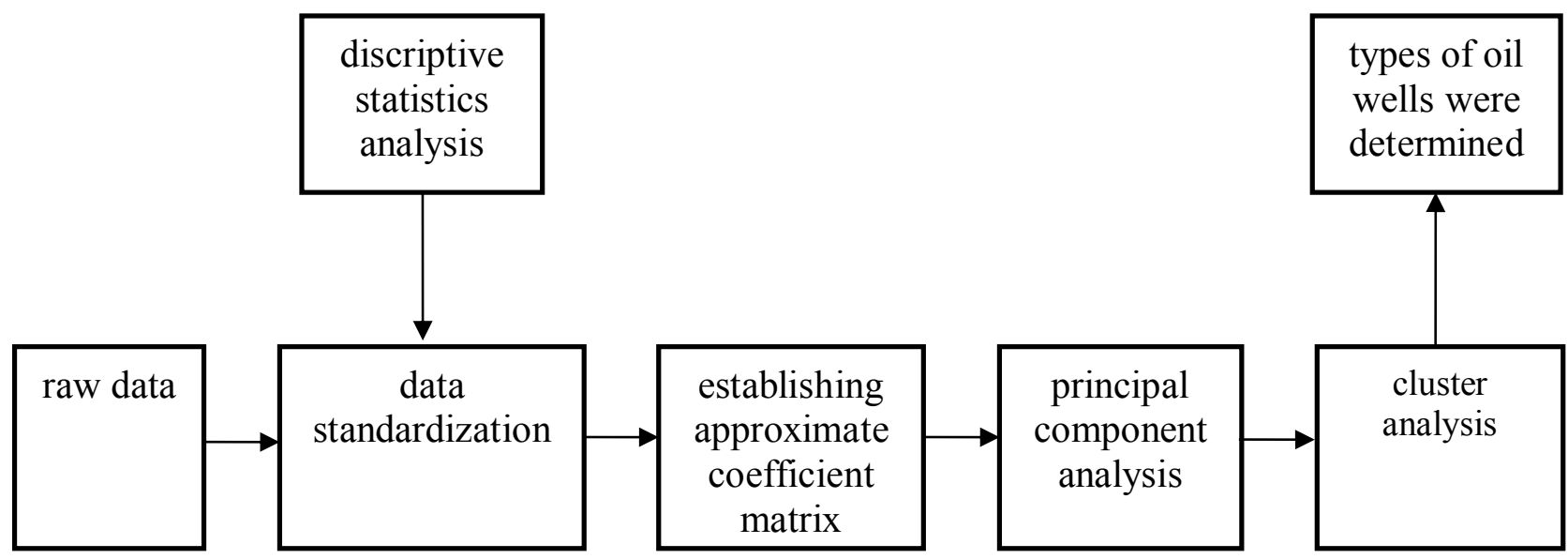

Fig. 1 Flow chart of cluster analysis

Principal component analysis and cluster analysis were the key parts of the whole process ${ }^{[13]}$. First, by linear combination, the original multiple indicatiors had become a few independent indicators that fully reflected the overall information, so as to make further analysis ${ }^{[14]}$. Second, the main factors that caused oil wells corrosion and scaling were determined by removing the dependent variable. Third, cluster analysis was used again to classify oil wells according to the differences among main factors $^{[15]}$. Finally, oil wells with the same main factors would be included in a same category.

\section{Principal component analysis of water quality data}

Water quality data of oil wells were made principal component analysis by using spss 19.0 software to find the main factors that caused corrosion and scaling in oil wells. Principal components were selected according to the order of contribution rate of different components, then the selected principal components were as weights for linear weighting ${ }^{[14]}$. They were sorted according to the score value ${ }^{[16]}$. Finally, the main influence factors of corrosion and scaling in oil wells were determined through quantifying and objectively weighting various factors, and eliminating the interrelated influence of each factor. Table 1 illustrates the variance contribution rate of eleven components. Cumulative variance contribution rate of the first four principal components reaches more than $70 \%$, and the initial eigenvalue are all greater than 1 , so the data of the first four principal components can represent most of the original data. The variance contribution of the first four principal components F1, F2, F3, and F4 are $35.240 \%, 14.196 \%, 11.631 \%$, and $9.617 \%$, respectively.

Table 2 is the initial factor load matrix obtained from the principal component analysis. It shows that salinity, $\mathrm{Cl}^{-}, \mathrm{Ca}^{2+}, \mathrm{Na}^{+}, \mathrm{HCO}_{3}{ }^{-}$have the highest loads on the first principal component $\mathrm{F} 1$, the load of them corresponds to $0.983,0.979,0.470,0.779$ respectively. $\mathrm{SO}_{4}{ }^{2-}$ and $\mathrm{Mg}^{2+}$ have the highest loads on the second principal component F2, the load of them corresponds to 0.827 and 0.704 respectively. SRB and $\mathrm{pH}$ have the highest loads on the third principal component $\mathrm{F} 3$, the load of them corresponds to 0.589 and 0.565 respectively. $\mathrm{CO}_{3}{ }^{2-}$ and free $\mathrm{CO}_{2}$ have the highest loads on the fourth principal component $\mathrm{F} 4$, the load of them corresponds to 0.694 and 0.604 respectively. 
Tab.1 Variance contribution rate

\begin{tabular}{c|c|c|c|c|c|c}
\hline \multirow{2}{*}{ Components } & \multicolumn{3}{|c|}{ Initial eigenvalue } & \multicolumn{3}{|c}{ Extraction square and loading } \\
\cline { 2 - 6 } & Total & $\begin{array}{c}\text { Variance } \\
\text { contribution } \\
{[\%]}\end{array}$ & $\begin{array}{c}\text { Cumulative } \\
\text { variance } \\
\text { contribution rate } \\
{[\%]}\end{array}$ & $\begin{array}{c}\text { Total } \\
\text { Variance } \\
\text { contribution } \\
{[\%]}\end{array}$ & $\begin{array}{c}\text { Cumulative } \\
\text { variance } \\
\text { contribution rate } \\
{[\%]}\end{array}$ \\
\hline 1 & 3.876 & 35.240 & 35.240 & 3.876 & 35.240 & 35.240 \\
2 & 1.562 & 14.196 & 49.436 & 1.562 & 14.196 & 49.436 \\
3 & 1.279 & 11.631 & 61.067 & 1.279 & 11.631 & 61.067 \\
4 & 1.058 & 9.617 & 70.684 & 1.058 & 9.617 & 70.684 \\
5 & .921 & 8.374 & 79.057 & & & \\
6 & .812 & 7.382 & 86.440 & & & \\
7 & .692 & 6.293 & 92.733 & & & \\
8 & .464 & 4.219 & 96.952 & & & \\
9 & .335 & 3.045 & 99.997 & & & \\
10 & .000 & .003 & 100.000 & & & \\
11 & $5.948 \mathrm{E}-8$ & $5.407 \mathrm{E}-7$ & 100.000 & & \\
\hline
\end{tabular}

Tab.2 Initial factor load matrix

\begin{tabular}{c|c|c|c|c}
\hline \multirow{2}{*}{} & \multicolumn{4}{|c}{ Components } \\
\cline { 2 - 5 } & 1 & 2 & 3 & 4 \\
\hline Salinity & .983 & -.013 & .098 & -.023 \\
$\mathrm{Cl}^{-}$ & .979 & -.033 & .092 & -.030 \\
$\mathrm{HCO}_{3}^{-}$ & .470 & -.123 & .394 & .232 \\
$\mathrm{CO}_{3}^{2-}$ & -.052 & -.100 & .291 & -.694 \\
$\mathrm{SO}_{4}^{2-}$ & .144 & .827 & -.199 & -.014 \\
$\mathrm{Ca}^{2+}$ & .779 & -.059 & -.208 & -.143 \\
$\mathrm{Mg}^{2+}$ & .245 & .704 & -.388 & -.166 \\
$\mathrm{Na}^{+}$ & .975 & -.043 & .120 & -.014 \\
$\mathrm{SRB}$ & -.006 & .429 & .589 & .061 \\
Free CO & .229 & -.122 & -.328 & .604 \\
$\mathrm{pH}$ & -.195 & .389 & .565 & .323 \\
\hline
\end{tabular}

Therefore, through integrating of Table 1 and Table 2, it can be concluded that F1 mainly reflects that corrosion and scaling in the first type wells were mainly caused by more salinity, $\mathrm{Cl}^{-}, \mathrm{Ca}^{2+}, \mathrm{Na}^{+}$ and $\mathrm{HCO}_{3}{ }^{-}$than other wells ${ }^{[17]}$. So, $\mathrm{F} 1$ could be used as salinity, $\mathrm{Cl}^{-}, \mathrm{Ca}^{2+}, \mathrm{Na}^{+}$and $\mathrm{HCO}_{3}{ }^{-}$corrosion and scaling identification factor. F2 mainly reflects that the corrosion and scaling in the second type wells were mainly caused by more $\mathrm{Mg}^{2+}$ and $\mathrm{SO}_{4}{ }^{2-}$ than other wells ${ }^{[18]}$. So, it could be used as $\mathrm{Mg}^{2+}$ and $\mathrm{SO}_{4}{ }^{2-}$ corrosion and scaling identification factor. $\mathrm{F} 3$ mainly reflects that the corrosion and scaling in the third type wells were mainly caused by more SRB and $\mathrm{pH}$ than other wells ${ }^{[19,20]}$. So, F3 could be used as SRB and $\mathrm{pH}$ corrosion and scaling identification factor. F4 mainly reflects that the corrosion and scaling in the fourth type wells were mainly caused by more $\mathrm{CO}_{3}{ }^{2-}$ and free $\mathrm{CO}_{2}$ than other wells ${ }^{[21]}$. So, it could be used as $\mathrm{CO}_{3}{ }^{2-}$ and free $\mathrm{CO}_{2}$ corrosion and scaling identification factor.

Data of the principal component score coefficient matrix (Table 3 ) and standardized data ( $Z$ value) were used to calculate the factor score of F1, F2, F3, F4 and F. The score of comprehensive principal component $\mathrm{F}$ could be concluded according to the four factor scores. The calculation steps are shown in formula (1), (2), (3), (4) and (5).

the factor score of $\mathrm{F} 1=0.254 \times \mathrm{Z}($ Salinity $)+0.253 \times \mathrm{Z}\left(\mathrm{Cl}^{-}\right)+\ldots \ldots-0.050 \times \mathrm{Z}(\mathrm{pH})$.

the factor score of $\mathrm{F} 2=-0.008 \times \mathrm{Z}$ (Salinity) $-0.021 \times \mathrm{Z}\left(\mathrm{Cl}^{-}\right)+\ldots \ldots+0.249 \times \mathrm{Z}(\mathrm{pH})$.

the factor score of $\mathrm{F} 3=0.077 \times \mathrm{Z}($ Salinity $)+0.072 \times \mathrm{Z}\left(\mathrm{Cl}^{-}\right)+\ldots \ldots+0.442 \times \mathrm{Z}(\mathrm{pH})$.

the factor score of $\mathrm{F} 4=-0.022 \times \mathrm{Z}(\mathrm{S})-0.028 \times \mathrm{Z}\left(\mathrm{Cl}^{-}\right)+\ldots . .+0.305 \times \mathrm{Z}(\mathrm{pH})$.

the comprehensive factor score of $\mathrm{F}=0.35240 \times \mathrm{F} 1+0.14196 \times \mathrm{F} 2+0.11631 \times \mathrm{F} 3+0.09617 \times \mathrm{F} 4$. 
Tab.3 Component score coefficient matrix

\begin{tabular}{c|c|c|c|c}
\hline & \multicolumn{4}{|c}{ Components } \\
\cline { 2 - 5 } & 1 & 2 & 3 & 4 \\
\hline Salinity & .254 & -.008 & .077 & -.022 \\
$\mathrm{Cl}^{-}$ & .253 & -.021 & .072 & -.028 \\
$\mathrm{HCO}_{3}^{-}$ & .121 & -.079 & .308 & .219 \\
$\mathrm{CO}_{3}^{2-}$ & -.013 & -.064 & .228 & -.656 \\
$\mathrm{SO}_{4}^{2-}$ & .037 & .530 & -.156 & -.014 \\
$\mathrm{Ca}^{2+}$ & .201 & -.038 & -.162 & -.135 \\
$\mathrm{Mg}^{2+}$ & .063 & .451 & -.303 & -.157 \\
$\mathrm{Na}^{+}$ & .251 & -.028 & .094 & -.013 \\
$\mathrm{SRB}^{2+}$ & -.002 & .275 & .460 & .057 \\
Free CO & .059 & -.078 & -.256 & .571 \\
$\mathrm{pH}$ & -.050 & .249 & .442 & .305 \\
\hline
\end{tabular}

\section{Clustering analysis of oil wells}

Taking the four principal components $(\mathrm{F} 1, \mathrm{~F} 2, \mathrm{~F} 3, \mathrm{~F} 4)$ which influenced the corrosion and scaling in oil wells as independent variables, different wells as the dependent variable, the level of corrosion and scaling was clustered by spss 19.0 statistical software. The distance between regions was calculated by Euclidean distance ward method. Then, the two wells with minimal distance (maximum similarity) were merged into one type by $\mathrm{Q}$ clustering ${ }^{[22]}$. The samples were weighted average, formed a new sample combination. The approximate coefficient matrix was calculated using the newly formed samples data. In this way, repeat the prior steps, until all the wells belong to one type ${ }^{[23]}$.

According to the variance analysis method in the software to verify the final classification is shown in Table 4. It can be known that when the oil wells are divided into four types, the similarity among types based on F1, F2, F3, and F4 is almost zero respectively, which suggests the clustering effect is the best. Thus, it is right that the oil wells are divided into four types according to the differences among F1, F2, F3 and F4.

Tab.4 Variance analysis

\begin{tabular}{l|ccc}
\hline & Two types & Three types & Four types \\
\hline Similarity among types based on F1 & 0.000 & 0.000 & 0.000 \\
Similarity among types based on F2 & 0.812 & 0.368 & 0.000 \\
Similarity among types based on F3 & 0.006 & 0.000 & 0.000 \\
Similarity among types based on F4 & 0.025 & 0.009 & 0.004 \\
\hline
\end{tabular}

\section{Results and discussion}

Integrating the results of principal component analysis and clustering analysis, the corrosion and scaling in oil wells of the oil production plant can be divided into four types. Table 5 shows classification of corrosion and scaling in different oil wells. The following section made further detailed analysis of corrosion and scaling reasons according to the water quality data and the scale analysis data of oil wells. Water analysis data of four types of wells are shown in Table 6. Scale morphology of typical oil wells is shown in Figure 2. Scale analysis data are shown in Table 7.

Tab.5 Classification of corrosion and scaling in different oil wells

\begin{tabular}{ccccc}
\hline $\begin{array}{c}\text { Category } \\
\text { the order } \\
\text { of scores })\end{array}$ & $\begin{array}{c}\text { The first type } \\
(\mathrm{F} 1>\mathrm{F}>\mathrm{F} 2>\mathrm{F} 3>\end{array}$ & $\begin{array}{c}\text { The second type } \\
(\mathrm{F} 2>\mathrm{F} 3>\mathrm{F}>\mathrm{F} 1>\end{array}$ & $\begin{array}{c}\text { The third type } \\
(\mathrm{F} 3>\mathrm{F} 2>\mathrm{F}>\mathrm{F} 4>\end{array}$ & $\begin{array}{c}\text { The fourth type } \\
(\mathrm{F} 4>\mathrm{F} 2>\mathrm{F} 3>\mathrm{F} 1>\end{array}$ \\
\hline \multirow{3}{*}{ wells } & $\mathrm{F} 4)$ & $\mathrm{F} 4)$ & $\mathrm{F} 1)$ & $\mathrm{F})$ \\
& $\mathrm{C} 31-58, \mathrm{C} 12-208$, & $\mathrm{C} 12-291, \mathrm{C} 19-3$, & $\mathrm{C} 19-5, \mathrm{C} 19-213$, & $\mathrm{C} 31-136, \mathrm{C} 31-65$, \\
& et al & C74-201, & $\mathrm{C} 30-60, \mathrm{C} 48-130$ & $\mathrm{C} 79-18, \mathrm{C} 19-100$ \\
& & et al & et al \\
\hline
\end{tabular}




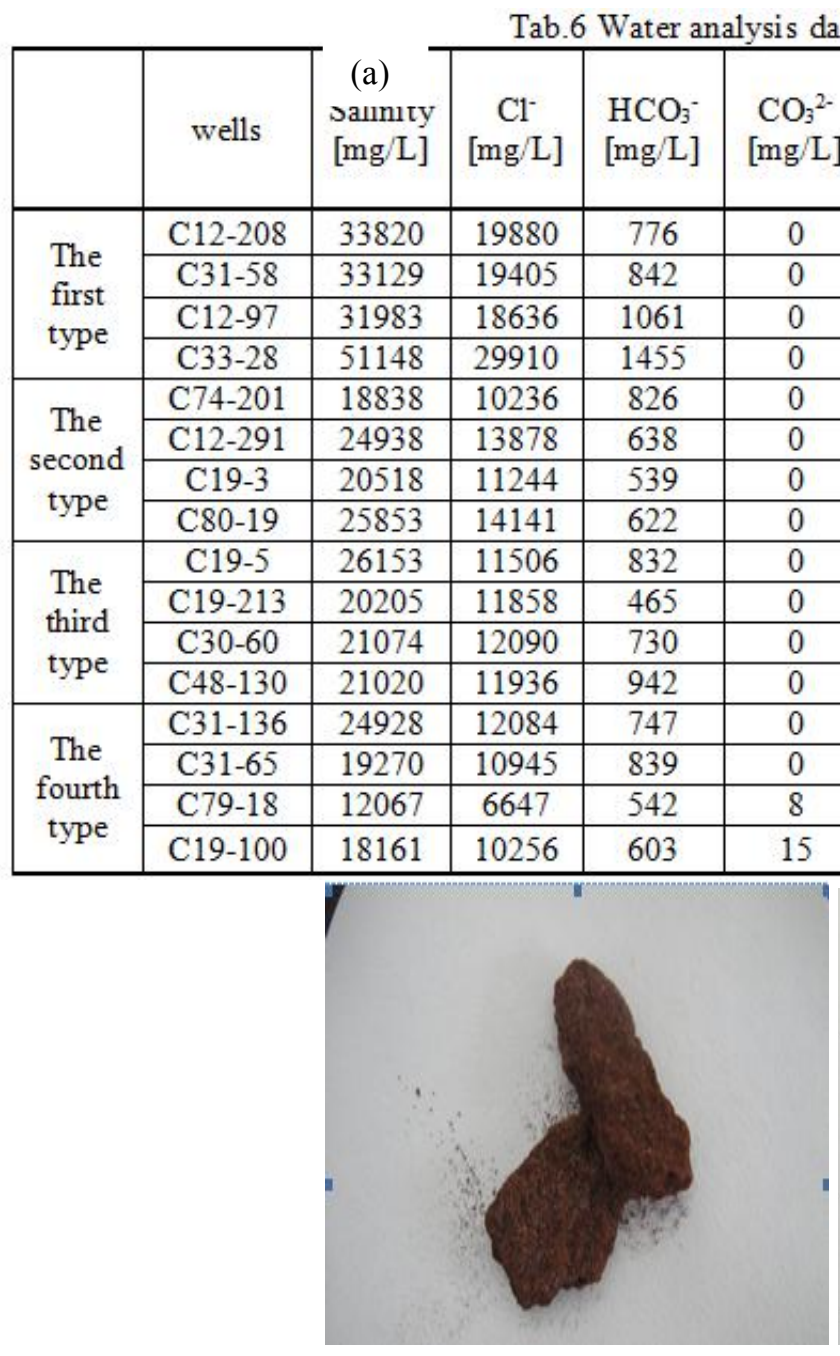

of four types of wells

(b)

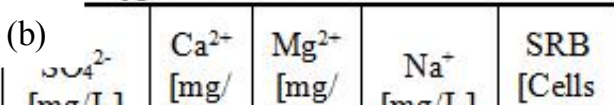
\begin{tabular}{|r|l|}
\hline $\begin{array}{r}\text { Free } \\
\mathrm{CO}_{2}\end{array}$ & \\
{$[\mathrm{mg} /$} & $\mathrm{pH}$ \\
$\mathrm{L}]$ & \\
\hline 52 & 6 \\
\hline
\end{tabular}

\begin{tabular}{|c|c|c|c|c|c|c|}
\hline$[\mathrm{mg} / \mathrm{L}]$ & $\begin{array}{c}\text { [mg } \\
\text { L] }\end{array}$ & $\begin{array}{c}\text { [mg } \\
\mathrm{L}]\end{array}$ & {$[\mathrm{mg} / \mathrm{L}]$} & [Cells & $\begin{array}{c}{[\mathrm{mg} /} \\
\mathrm{L}]\end{array}$ & $\mathrm{pH}$ \\
\hline 28 & 360 & 61 & 12715 & 0 & 52 & 6 \\
\hline 27 & 340 & 61 & 12455 & 0 & 47 & 6 \\
\hline
\end{tabular}

\begin{tabular}{|c|c|c|c|c|c|c|}
\hline 9 & 453 & 0 & 11825 & 0 & 52 & 6 \\
\hline 0 & 1027 & 12 & 18744 & 0 & 33 & 6 \\
\hline 624 & 511 & 150 & 6490 & 5 & 58 & 6 \\
\hline 841 & 343 & 88 & 9149 & 0 & 15 & 7 \\
\hline 700 & 399 & 363 & 7272 & 9 & 15 & 6 \\
\hline 1233 & 356 & 586 & 8915 & 0 & 10 & 6 \\
\hline 124 & 60 & 53 & 13579 & 25 & 20 & 8 \\
\hline 47 & 178 & 58 & 7600 & 25 & 32 & 6 \\
\hline 15 & 98 & 22 & 8110 & 25 & 0 & 7 \\
\hline 18 & 170 & 49 & 7890 & 25 & 0 & 7 \\
\hline 98 & 306 & 82 & 11612 & 0 & 160 & 6 \\
\hline 72 & 170 & 65 & 7179 & 0 & 107 & 6 \\
\hline 288 & 246 & 30 & 4314 & 0 & 61 & 6 \\
\hline 320 & 162 & 27 & 6794 & 0 & 53 & 6 \\
\hline
\end{tabular}

(c)

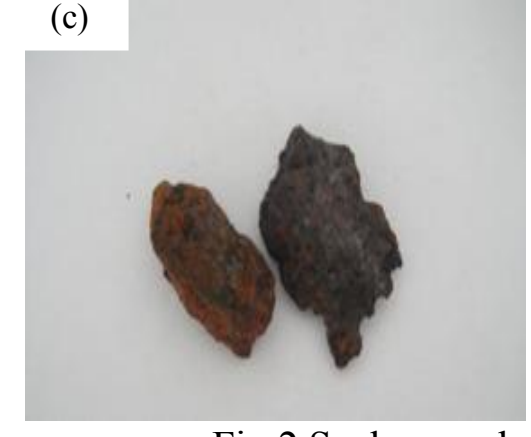

Fig.2 Scale morphology of typical oil wells

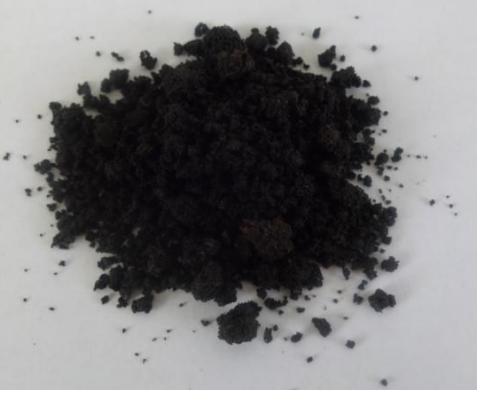

(d)

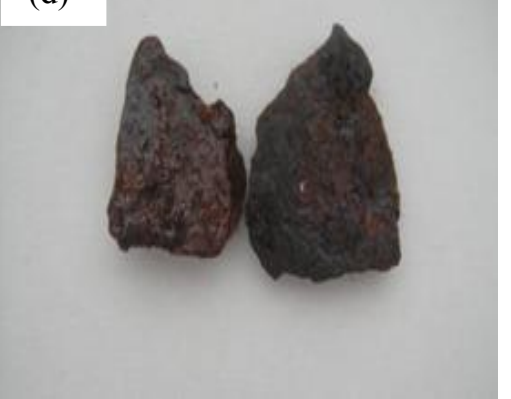

(a) C33-28 well (b) C80-19 well (c) C19-213well (d) C31-136 well

It can be known that the salinity of the first type wells are up to $51148 \mathrm{mg} / \mathrm{L}$ higher than other types, $\mathrm{Cl}^{-}$content is $18636-29910 \mathrm{mg} / \mathrm{L}, \mathrm{Ca}^{2+}$ content is $340-1027 \mathrm{mg} / \mathrm{L}, \mathrm{HCO}_{3}{ }^{-}$content is $776-1455 \mathrm{mg} / \mathrm{L}$. From Fig.2(a), it can be seen that the scale color is reddish brown, texture is hard. And a large number of bubbles appeared in acid dissolution, the dissolution was yellow green with no smell of rotten eggs. Then according to the scale analysis data of C33-28 well (Tab.7), it can be known that $\mathrm{Ca}^{2+}$ and $\mathrm{Mg}^{2+}$ content are higher than other wells, and $\mathrm{Fe}^{3+}, \mathrm{Fe}^{2+}$ content are relatively low. Thus, it can be concluded that the first type wells were mainly with calcium carbonate scaling, meanwhile existed $\mathrm{Cl}^{-}$ electrochemical corrosion ${ }^{[17]}$. The salinity of the second type wells are relatively low, $\mathrm{SO}_{4}{ }^{2-}{\mathrm{and} \mathrm{Mg}^{2+}}^{2+}$ content are higher than other types, $\mathrm{SO}_{4}{ }^{2-}$ content is $624-1233 \mathrm{mg} / \mathrm{L}, \mathrm{Mg}^{2+}$ content is $53-586 \mathrm{mg} / \mathrm{L}$. From Fig.2(b), it can be seen that the scale color is black, texture is soft. And a few bubbles appeared in acid dissolution, the dissolution was yellow green with no smell of rotten eggs. Then according to the scale analysis data of C80-19 well (Tab.7), it can be known that the content of corrosion products 
$\mathrm{Fe}^{3+}, \mathrm{Fe}^{2+}$ and $\mathrm{Ca}^{2+}, \mathrm{Mg}^{2+}$ content are relatively high. So, the second type wells were mainly with $\mathrm{SO}_{4}{ }^{2-}$ electrochemical corrosion ${ }^{[18]}$, meanwhile existed a small amount of calcium carbonate and magnesium carbonate scaling. SRB and $\mathrm{pH}$ content of the third type wells are higher than other types, $\mathrm{SRB}$ content is $25 \mathrm{mg} / \mathrm{L}$, and $\mathrm{pH}$ is $6-8$. From Fig.2(c), it can be seen that the scale color is black with red, texture of most of the sample is soft. When the sample was placed in acid solution, a few bubbles appeared, and the solution became yellow green with no smell of rotten eggs. Then according to the scale analysis data of C19-213 well (Tab.7), it can be known that $\mathrm{Fe}^{3+}$ and $\mathrm{Fe}^{2+}$ content are relatively high, and $\mathrm{Ca}^{2+}$ content is a little. Thus, it can be concluded that corrosion and scaling in the third type wells were mainly caused by SRB and $\mathrm{pH}$ corrosion ${ }^{[19,20]}$ and a little calcium carbonate scaling. The salinity of the fourth type wells are the lowest, but $\mathrm{CO}_{3}{ }^{2-}$ and free $\mathrm{CO}_{2}$ content are higher than other types, $\mathrm{CO}_{3}{ }^{2-}$ content is $0-15 \mathrm{mg} / \mathrm{L}$, free $\mathrm{CO}_{2}$ content is $53-160 \mathrm{mg} / \mathrm{L}$. From Fig.2(d), it can be seen that the scale color is black with red, texture of most of the sample is soft. And a few bubbles appeared in acid dissolution, the dissolution was yellow green with no smell of rotten eggs. Then according to the scale analysis data of C31-136 well (Tab.7), it can be known that the content of corrosion products $\mathrm{Fe}^{3+}, \mathrm{Fe}^{2+}$ are relatively high, and $\mathrm{Ca}^{2+}$ content is a little. So, it can be concluded that corrosion and scaling in the fourth type wells were mainly caused by free $\mathrm{CO}_{2}$ electrochemical corrosion ${ }^{[21]}$ and a little calcium carbonate scaling.

Tab.7 Scale analysis data of typical oil wells

\begin{tabular}{|c|c|c|c|c|c|c|c|c|}
\hline & $\begin{array}{c}\text { Typical } \\
\text { wells }\end{array}$ & $\begin{array}{c}\text { Water, } \\
\text { volatile and } \\
\text { organics } \\
{[\%]}\end{array}$ & $\begin{array}{c}\text { Inorganic } \\
{[\%]}\end{array}$ & $\begin{array}{c}\text { Acid } \\
\text { insoluble } \\
\text { substance } \\
{[\%]}\end{array}$ & $\begin{array}{c}\mathrm{Ca}^{2+} \\
{[\%]}\end{array}$ & $\begin{array}{c}\mathrm{Mg}^{2+} \\
{[\%]}\end{array}$ & $\begin{array}{c}\mathrm{Fe}^{3+} \\
{[\%]}\end{array}$ & $\begin{array}{c}\mathrm{Fe}^{2+} \\
{[\%]}\end{array}$ \\
\hline $\begin{array}{c}\text { The first type } \\
\text { well }\end{array}$ & $\mathrm{C} 33-28$ & 4.3 & 48.2 & 3.0 & 20.86 & 2.7 & 12.0 & 5.9 \\
\hline $\begin{array}{c}\text { The Second } \\
\text { type well }\end{array}$ & $\mathrm{C} 80-19$ & 4.8 & 20.7 & 7.3 & 9.86 & 5.18 & 20.3 & 28.5 \\
\hline $\begin{array}{c}\text { The third type } \\
\text { well }\end{array}$ & $\mathrm{C} 19-213$ & 21.6 & 7.1 & 4.4 & 4.2 & 0.6 & 5.3 & 52.5 \\
\hline $\begin{array}{c}\text { The fourth type } \\
\text { well }\end{array}$ & $\mathrm{C} 31-136$ & 20.2 & 13.6 & 0 & 6.0 & 2.5 & 8.4 & 42.4 \\
\hline
\end{tabular}

\section{Application in the field}

Finally, oil wells dosing were applied in the field according to the classification. The dosing effect is obvious. The corrosion inhibition rate is $70 \%$ above, scaling inhibition rate for calcium carbonate scale is $90 \%$ above. Average pump period extends from 181 days to 873 days. According to the production of oil wells, it can be known that pumping caused by corrosion and scaling in most of oil wells seldom occur after dosing. The amount of pump reduction adds up to 395 wells. Costs savings of all the wells add up to 5390 thousands.

\section{Conclusions}

The corrosion and scaling in oil wells were divided into four classifications by using principal component analysis and cluster analysis. And dosing effects in the field is obvious according to the classification. It can save a lot of management costs, and realize the large-scale management of oil wells.

\section{References}

[1] M.E. El-Dahshan: Desalination, Vol. 138 (2001), p. 371-377

[2] Zhiqiang Wang, Qingyi Nan, Wei Zhang, Zhongtai Tian, Shengli Wang, Ruimin Cao: Oil Drilling \& Production Technology, Vol. Suppl. (2006), p. 42-45 (In Chinese) 
[3] Qingzhen Du, Gang Xie, Meihong Yang, Yunping Zheng, Zhongtai Tian: Journal of Southwest Petroleum University(Science \& Technology Edition), Vol. 35 ( 2013), p. 142-148 (In Chinese)

[4] Yongbin Xiang, Chuan Liang, Yuan Lin: Journal of Sichuan university (Engineering science edition), Vol. 46 (2014), p. 7-12 (In Chinese)

[5] Jingxin SU, Chunxiao Zhang, Tianjie Xu: Corrosion \& protection, Vol. 33 (2012), p. $708-714$ (In Chinese)

[6] Gehong Wu, Caisong Gao, Yumin Liu: Fault-block oil \&gas field, Vol. 8 (2001), p. 36-37 (In Chinese)

[7] Xue Sun, Chunhua Hou: Journal of Southwest Petroleum University (Social Sciences Edition), Vol. 16 (2014), p. 6-10 (In Chinese)

[8] Shuoliang Wang, Hanqiao Jiang, Junjian Li, et al: Oil drilling \& production technology, Vol. 33 (2011), p. 61-64 (In Chinese)

[9] Weiyan Dai, Shaohua Li, Jun Wang, et al: Fault-block oil \& gas field, Vol. 22 (2015), p. 492-496 (In Chinese)

[10] Mark A. Engle, Madalyn S. Blondes: Journal of Geochemical Exploration, Vol. 141(2014), p. $61-70$

[11] Yihua Zhong, Jiao Zhao: Petroleum, Vol. 2 (2016) , p.307-312

[12]Rakesh Agrawal, Johannes GehrkeDimitrios GunopulosPrabhakar Raghavan: Data Mining and Knowledge Discovery, Vol. 11(2005), p. 5

[13]Xian Shan, Yanliang Cao: China management informationization, Vol. (2010), p. 38-41 (In Chinese)

[14]A.A. Miranda, Y.-A. Le Borgne, and G. Bontempi: Neural Processing Letters, Springer, Vol. 27 (2008), p. 1-14

[15]Xingde Huang, Ping Yu, Yunbai Luo: Industrial water treatment, Vol. 22 (2002), p. 12-15 (In Chinese)

[16]Chengkang Gao, Jincheng Shang, Dahe Jiang: Water resources protection, Vol. 6 (2004), p. 28-34 (In Chinese)

[17] Kunhu Wu, Liqun Zhu, Weiping Li, Huicong Liu: Corrosion Science, Vol. 52 (2010), p. 2244-2249

[18] Yasuyuki Kobayashi, Yutaka Fujiwara: Electrochimica Acta, Vol. 51 (2006) ,p. 4236-4242

[19] Shuan Liu, Huyuan Sun, Lijuan Sun, Huiji Fan: Corrosion Science, Vol. 65 (2012) , p. 520-527

[20]D. Starosvetsky, J. Starosvetsky, R. Armon, Y. Ein-Eli: Corrosion Science, Vol. 52 (2010), p. 1536-1540

[21]Jason D. Laumb, Kyle A. Glazewski, John A. Hamling, Alexander Azenkeng, Theresa L. Watson: International Journal of Greenhouse Gas Control, Vol. 54(2016), p. 479-489

[22]Zhijun Gao, Lang Li, Ting Wu: Petroleum geology and engineering, Vol. 23 (2009), p. 64-68 (In Chinese)

[23]Lianxin Yuan, Yong Yu: Environmental science \& technology, Vol. 34 (2011), p. 267-270 (In Chinese) 